\title{
THE EFFECT OF HIGH PERFUSION PRESSURES ON THE GRANULATION OF JUXTAGLOMERULAR CELLS IN AN ISOLATED KIDNEY*
}

\author{
By LOUIS TOBIAN, ALICE TOMBOULIAN AND JEANETTE JANECEK \\ (From the Department of Internal Medicine, University of Minnesota School of Medicine, and \\ the University of Minnesota Hospitals, Minneapolis, Minn.)
}

(Submitted for publication October 10, 1958; accepted November 25, 1958)

In our previous studies on the granulation of juxtaglomerular cells, we were impressed with several experiments in which a kidney was perfused with blood at a high pressure and had a striking decrease in the juxtaglomerular granulation (1). Conversely, in other situations where the pressure of the blood perfusing the kidney was reduced, the juxtaglomerular granulation tended to increase (1). These relationships can easily be indirect or coincidental, and it seemed of interest to find out whether changes in perfusion pressure can directly alter the granulation of these cells.

\section{METHODS}

In this experiment, we would have preferred to test perfusion pressures both higher and lower than normal. However, when a clip is allowed partially to constrict one renal artery in a rat for 24 hours, no increase in juxtaglomerular granulation occurs in the clipped kidney at the end of the 24 hours, even though such an increase usually occurs after a few weeks. This experiment suggested that lowering the perfusion pressure would not produce any detectable changes within the space of a four hour perfusion experiment. Hence, we were prompted to compare perfusion pressures slightly below normal with distinctly high perfusion pressures. The design of our perfusion apparatus is illustrated diagrammatically in Figure 1. A normal male Wistar rat (A) provided oxygenated and "biochemically supported" blood through its carotid artery (B) to some Tygon tubing (C) which ran through a Sigmamotor pump (D). The pump could be regulated to increase or decrease the pressure of blood flowing into the Tygon tubing distal to it, which was connected to the renal artery of an isolated normal rat kidney (E). The isolated kidney was always obtained from a normal male Wistar rat and was removed in such a way that it never had more than 15 seconds of ischemia during the "hooking-up" period before being placed in the warm chamber $(F)$. This warm chamber contained a space which just fitted the kidney and served

* This investigation was supported by a grant from the American Heart Association and by Grant No. H 2008 from the National Heart Institute, United States Public Health Service. to maintain it at body temperature. The isolated kidney was wrapped in a Saran plastic film to reduce evaporation and to prevent any contact with the potentially toxic heavy metals of the warm chamber. A side arm in the tubing between the pump and the kidney was connected to a mercury manometer (G) which was monitored continuously to determine whether the pump required any adjustment to maintain a given constant perfusion pressure. The blood leaving the isolated kidney via the renal vein went through polyethylene tubing to a miniature Murphy drip apparatus $(\mathrm{H})$, which provided an estimate of the magnitude of flow. From there, it returned through some more polyethylene tubing to the jugular vein of the original rat (I).

Heparin was added to the circulating blood to prevent clotting. The "blood donor" rat (A) was anesthetized with Nembutal ${ }^{\circledR}$. His trachea was cannulated to prevent any airway obstruction. The perfusions lasted from one to four hours. Sixteen kidneys were perfused at about $85 \mathrm{~mm}$. $\mathrm{Hg}$, a level on the low side of normal but one at which renal autoregulation is considered to be intact (2). These perfusions at a relatively low pressure were compared with 21 other experiments where the perfusion pressure varied between 167 and $192 \mathrm{~mm}$. $\mathrm{Hg}$.

When the isolated kidney intended for perfusion was first obtained, the opposite kidney was also removed and subsequently sectioned. The juxtaglomerular indices in both kidneys were estimated using the Hartroft method (3) as employed in our laboratory (1). Six different sections from each kidney were counted and then averaged, thereby increasing our precision two and one-half

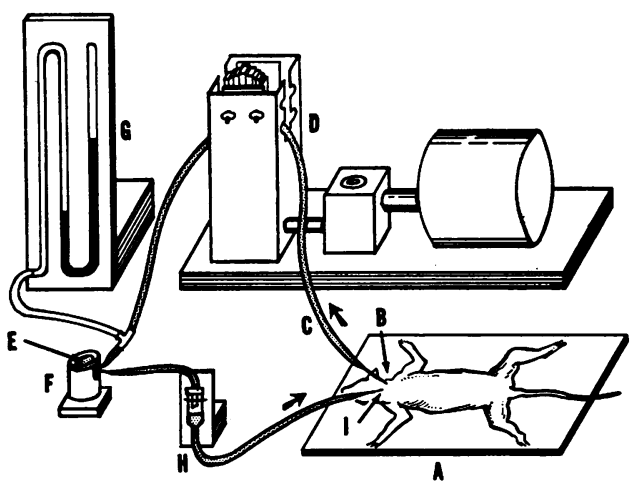

Fig. 1. Diagram of Apparatus Used in Perfusing an ISOLATED RAT KIDNEY 
times over that which was obtained when counting single sections. It was assumed that the two kidneys would have approximately the same juxtaglomerular index. This assumption was tested (see under Results below). By determining the juxtaglomerular index of the isolated kidney at the end of the perfusion and by comparing it to the juxtaglomerular index of the control opposite kidney from the same rat, one can get a good estimate of the changes in juxtaglomerular granulation that occurred during the perfusion.

Since the peristaltic action of the Sigmamotor pump is more active during high pressure perfusions, more hemolysis would occur. To control this factor, some cross-matched homologous rat blood was homogenized, and given portions were injected into the circulation every 10 minutes during some of the low pressure perfusions. This provided the same degree of hemolysis that was found at the termination of the "high pressure" perfusions.

We were curious to know whether there was some humoral factor being introduced into the renal vein of the isolated kidney that was influencing the granulation of the juxtaglomerular cells. To investigate this possibility, the juxtaglomerular index was determined in a number of kidneys of "blood donor" rats ("A" in Figure 1), as well as in the isolated kidney.

To determine whether a change in adrenal secretion had any effect on the experiment, a few "blood donor" rats were totally adrenalectomized just before beginning the experiment. These adrenalectomized rats were given one injection of $3 \mathrm{mg}$. of cortisone acetate subcutaneously just after the adrenalectomy. A few such adrenalectomized rats were used in high as well as "low pressure" perfusions. Any given rat might be used in either a "high pressure" or a "low pressure" perfusion experiment but never in both.
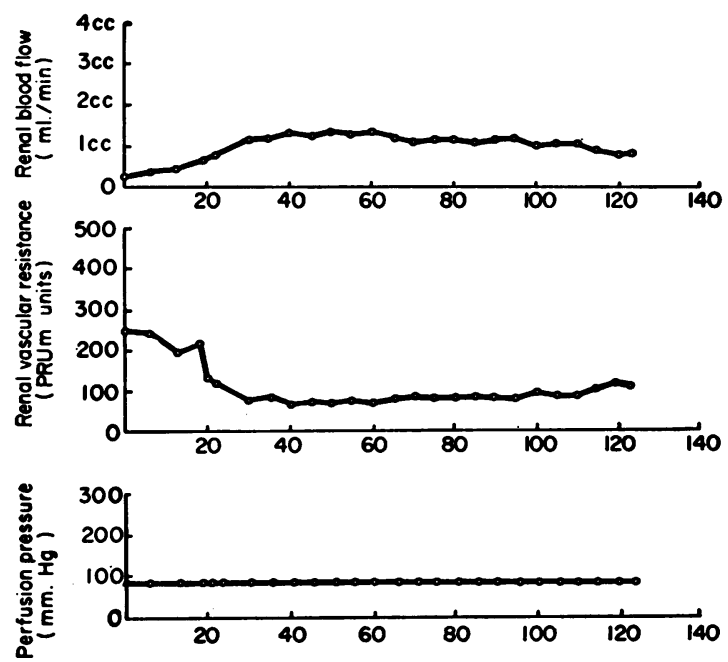

Fig. 2. Perfusion Pressure, Renal Blood Flow, and Renal Vascular Resistance in a Typical "Low Pressure" Perfusion EXPERIMENT
The blood flow in the isolated kidneys varied between 0.2 and $4.0 \mathrm{ml}$. per minute. The resistance in the renal vascular bed was estimated by the following equation:

$$
\text { Resistance }=\frac{\begin{array}{c}
\text { Renal arterial pressure }(\mathrm{mm} . \mathrm{Hg}) \text {-renal } \\
\text { venous pressure }(\mathrm{mm} . \mathrm{Hg})
\end{array}}{\text { renal blood flow }(\mathrm{ml} . \text { per } \mathrm{min} .)}
$$

The resistance was measured in so-called " $P R U_{m}$ " resistance units (mm. $\mathrm{Hg}$ per ml. per minute) (4). The resistance in the isolated kidneys varied between 60 and 500 units. At the beginning of each experiment, the perfusion pressure was kept around 85 to $95 \mathrm{~mm}$. $\mathrm{Hg}$ and the resistance in the isolated kidneys averaged 224 units and ranged between 100 and 406 units. If the perfusion pressure was maintained at this relatively low level, the resistance in the renal vascular bed usually dropped to around 100 units after 20 minutes, with a concomitant increase in blood flow. The resistance in these kidneys would then gradually increase about 50 units after one and one-half hours of perfusion. Figure 2 illustrates a typical perfusion at lower pressure.

When the kidneys were perfused at the higher pressures (167 to $192 \mathrm{~mm}$. $\mathrm{Hg}$ ), half of them would show an attempt at "autoregulation" with the resistance in the renal vascular bed rising 200 to 300 units shortly after the higher perfusion pressure was applied. Eventually, all the kidneys perfused at the higher pressures had a drop in resistance to levels between 50 and 100 resistance units. After 30 to 80 minutes in this state of lowered vascular resistance, the renal resistance would gradually begin to rise and would continue up to levels of 350 to 500 units. At this point the blood flow in the isolated kidneys was down to the starting level and the perfusions were terminated. A typical "high pressure" experiment is illustrated in Figure 3.

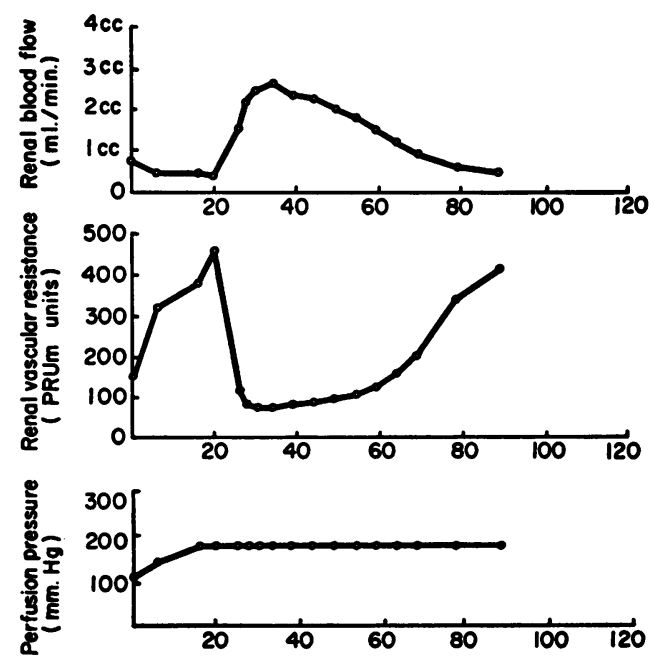

Fig. 3. Perfusion Pressure, Renal Blood Flow, and Renal Vascular Resistance in a Typical "High Pressure" Perfusion Experiment 
EFFECT OF ARTERIAL PRESSURE ON JUXTAGLOMERULAR CELLS

TABLE I

Perfusion experiments using high pressures

\begin{tabular}{|c|c|c|c|c|c|c|}
\hline $\begin{array}{l}\text { Experi- } \\
\text { ment* }\end{array}$ & $\begin{array}{l}\text { Perfusion } \\
\text { pressure }\end{array}$ & Time & $\begin{array}{l}\text { JG index of } \\
\text { control } \\
\text { kidney } \\
\left(J G_{0}\right)\end{array}$ & $\begin{array}{l}\text { JG index of } \\
\text { isolated } \\
\text { perfused } \\
\text { kidney } \\
\left(\mathrm{JG}_{\mathrm{p}}\right)\end{array}$ & $\begin{array}{l}\text { "\% of change" } \\
\left(\frac{\mathrm{JG}_{\mathrm{p}}}{\mathrm{JG}_{\mathrm{0}}} \times 100\right)\end{array}$ & $\begin{array}{l}\text { JG index of } \\
\text { kidney of } \\
\text { "blood donor" } \\
\text { rat }\end{array}$ \\
\hline & $m m . H g$ & $\min$. & & & & \\
\hline A & 178 & 130 & 35 & 7 & 20 & \\
\hline $\mathrm{B}$ & 167 & 175 & 34 & 9 & 26 & \\
\hline $\mathrm{C} \dagger$ & 182 & 130 & 27 & 10 & 37 & 32 \\
\hline D & 188 & 70 & 41 & 16 & 39 & \\
\hline $\mathrm{E}$ & 182 & 77 & 51 & 21 & 41 & 34 \\
\hline $\mathbf{F}$ & 182 & 90 & 45 & 19 & 42 & \\
\hline$G$ & 192 & 128 & 36 & 17 & 47 & \\
\hline $\mathrm{H}$ & 173 & 100 & 48 & 23 & 48 & \\
\hline $\mathrm{I}$ & 178 & 130 & 48 & 23 & 48 & \\
\hline $\mathrm{J} \dagger$ & 182 & 85 & 44 & 25 & 57 & 44 \\
\hline $\mathbf{K}$ & 182 & 131 & 49 & 28 & 57 & 39 \\
\hline $\mathrm{L}$ & 182 & 185 & 42 & 26 & 62 & 49 \\
\hline $\mathbf{M}$ & 182 & 240 & 56 & 36 & 64 & \\
\hline $\mathbf{N}$ & 167 & 232 & 43 & 28 & 65 & \\
\hline $\mathrm{O}$ & 173 & 140 & 49 & 34 & 69 & \\
\hline $\mathrm{P} \dagger$ & 178 & 110 & 58 & 42 & 72 & 42 \\
\hline$Q$ & 188 & 115 & 44 & 32 & 73 & \\
\hline R & 173 & 140 & 51 & 40 & 78 & \\
\hline $\mathrm{S}$ & 182 & 85 & 45 & 37 & 82 & 33 \\
\hline$T$ & 192 & 60 & 41 & 35 & 85 & \\
\hline $\mathbf{U}$ & 188 & 75 & 40 & 44 & 110 & \\
\hline \multirow{2}{*}{\multicolumn{3}{|c|}{$\begin{array}{l}\text { Mean } \\
\text { Standard deviation }\end{array}$}} & 44 & 26 & 58 & 39 \\
\hline & & & \pm 7.41 & \pm 10.86 & \pm 21 & \pm 6.38 \\
\hline
\end{tabular}

* Listed in the order of increasing "per cent of change."

$\dagger$ The "blood donor" rat was adrenalectomized before commencing the experiment.

There was a period of lowered vascular resistance in the middle of all the perfusions. In the perfusions at high pressures the maximum blood flow in the kidneys averaged $2.6 \mathrm{ml}$. per minute. In the perfusions at 85 to 95 $\mathrm{mm}$. $\mathrm{Hg}$, the maximum flows averaged $1.0 \mathrm{ml}$. per minute.

\section{RESULTS}

Tables I and II give the results for each individual experiment. They give the perfusion pressure, the length of the perfusion, and the juxtaglomerular (JG) indices for the control kidney and the isolated perfused kidney as well as the "per cent of change" between the two. In some instances, they give the JG index of a kidney residing in the "blood donor" rat which provided the oxygenated blood. The experiments with perfusions at high pressures are described in Table I. Those at lower pressures are shown in Table II. In the experiments with perfusion at high pressure, there was a highly significant degree of degranulation of the juxtaglomerular cells as a result of the perfusion $\left(p<10^{-8}\right)$. The juxtaglomerular index dropped from a mean of 44 in the control kidney to a mean of 26 in the perfused kidney. This is to be contrasted with the perfusions at lower pressures. The control kidneys had a mean juxtaglomerular index of 43 , while the kidneys perfused at the lower pressure also had a mean juxtaglomerular index of 43. Thus, perfusion at higher pressures caused significant degranulation, while perfusion at lower pressures did not. Also in Tables I and II, the JG index of each perfused kidney is presented as a given percentage of the JG index of its own control kidney $\left(\mathrm{JG}_{\mathrm{p}} / \mathrm{JG}_{\mathrm{c}} \times 100\right)$. Calculating the results in this way cancels out the inherent variation in the JG indices of the control kidneys from rat to rat. The kidneys perfused at the lower pressures averaged 100 per cent of their control values, indicating that they had virtually the same JG indices as their control kidneys. On the other hand, the kidneys perfused at the higher pressures averaged only 58 per cent of their control kidneys. When this difference was analyzed statistically, it proved to be highly significant $\left(p<10^{-12}\right)$. Some of the perfusions at the higher pressure continued for little more than an hour. In these relatively 
TABLE II

Perfusion experiments using low pressures

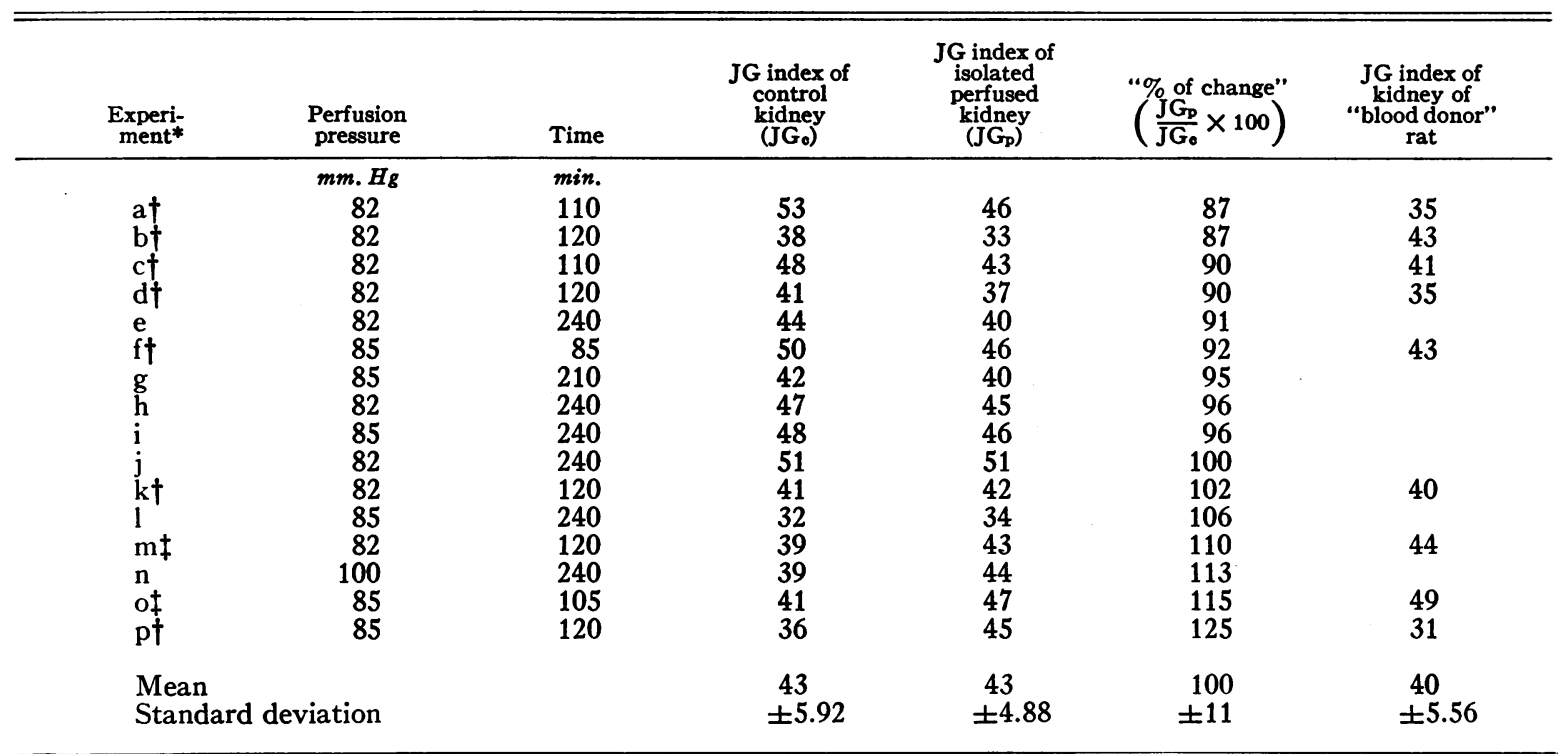

* Listed in the order of increasing "per cent of change."

t Homogenized matched blood was given intravenously to the "blood donor" rat.

¥ The "blood donor" rat was adrenalectomized before commencing the experiment.

short perfusions, a sizable drop in juxtaglomerular granulation did not always occur.

In comparing the perfused kidney with the control kidney, we assumed that the indices of the two kidneys would be quite similar at the start of the experiment. This assumption was tested in five rats (see Table III) and the two kidneys in any given rat never differed by more than 21 per cent.

Since adrenalectomy increases the granulation of the juxtaglomerular cells and desoxycorticosterone decreases it $(1,3,5)$, the adrenals obviously affect juxtaglomerular granulation and it seemed important to determine whether an increased rate of secretion by intact adrenals was necessary to

TABLE III

Juxtaglomerular granulation of the right and left kidneys of normal rats

\begin{tabular}{ccc}
\hline \hline $\begin{array}{c}\text { Rat } \\
\text { no. }\end{array}$ & $\begin{array}{c}\text { Juxtaglomerular } \\
\text { index of right } \\
\text { kidney }\end{array}$ & $\begin{array}{c}\text { Juxtaglomerular } \\
\text { index of left } \\
\text { kidney }\end{array}$ \\
\hline 1 & 38 & 39 \\
2 & 38 & 40 \\
3 & 40 & 34 \\
4 & 35 & 43 \\
5 & 50 & 52 \\
Mean & 40 & 41 \\
\hline
\end{tabular}

get the degranulation during perfusions at high pressure. Five rats were adrenalectomized and given cortisone acetate just before serving as the blood donors in the experiment. Three of the rats were utilized in perfusions at high pressure and significant degranulation occurred in the perfused kidney in each instance (see Table I). The other two adrenalectomized rats were utilized in perfusions at lower pressures (see Table II). In both rats, no degranulation whatsoever took place. These experiments rule out fairly well the possibility that an augmented secretion from the adrenals is responsible for the juxtaglomerular degranulation in the isolated kidney.

The possibility also arose that perfusion at high pressure causes the isolated kidney to release a humoral substance into the blood leaving its renal vein. Such a substance could directly or indirectly cause the reduction of juxtaglomerular granulation in the isolated kidney. Such a humoral substance would also be expected to produce a degranulation of the juxtaglomerular cells of the kidneys residing within the "blood donor" rat which is providing the oxygenated blood. However, the average index of such kidneys from seven experiments utilizing perfusion at high pressure was 39 , while the average index of 
such kidneys from nine experiments with perfusions at lower pressures was 40 (Tables I and II). Since this difference is negligible, the possibility that a humoral substance in the general circulation produces the degranulation at high pressures is remote.

Varying degrees of hemolysis occurred during the perfusion experiments. In general, there was more hemolysis during the perfusions at higher pressure. However, some experiments at the higher pressures had very little hemolysis and the typical degranulation of the juxtaglomerular cells still occurred. Moreover, given portions of matched hemolyzed blood were injected into the general circulation every $10 \mathrm{~min}$ utes in seven of the "low pressure" perfusion experiments. This introduction of hemolyzed blood provided more hemolysis than was seen in any of the experiments with perfusions at high pressure and still no significant degranulation occurred in the juxtaglomerular cells of the isolated kidney (Table II). It would appear that the juxtaglomerular degranulation in the perfusions at high pressure is not related to hemolysis.

\section{DISCUSSION}

The data here strongly support the hypothesis that an increase in perfusion pressure brings about a degranulation of the juxtaglomerular cells. Since the higher perfusion pressures were associated on the average with higher renal blood flows, the degranulation could be primarily related to flow rather than pressure. A number of rats had maximum renal flows of less than 2 ml. per minute during perfusions at high pressure and still had significant degranulation. On the other hand, one rat had a renal flow of about $2 \mathrm{ml}$. per minute with a perfusion pressure of 85 $\mathrm{mm}$. Hg. There was no significant change in juxtaglomerular granulation in this instance. Nevertheless, these kidneys might have had quite a different flow at higher or lower perfusion pressures. Hence, one cannot say with complete assurance that the degranulation is strictly dependent on the higher pressure. A higher renal blood flow or a higher rate of glomerular filtration, either of which could have resulted from a higher perfusion pressure, could be partly responsible for the degranulation.
However, the observations are quite compatible with the theory that the juxtaglomerular cells residing within the walls of the afferent glomerular arterioles can act as stretch receptors, changing their rate of secretion as the arteriolar wall changes its degree of stretch. Varying the perfusion pressure would be expected to produce just such an alteration in the stretch of the afferent arterioles.

In the mammalian circulation, the pressure in the arterial system mechanically stimulates baroreceptors in the carotid sinus, in the aortic arch, and in or near the arteries supplying the pancreas and intestines (6). It would seem that the juxtaglomerular cells constitute still another possible receptor area for the appreciation of changes in blood pressure. Such a theory need not imply that mechanical factors are the only stimuli for the juxtaglomerular cells. It is obviously quite possible that the concentration of mineralo-corticoids or of sodium ions in the extracellular fluid could also be important in determining the rate of secretion of the JG cells. The possible functions of these cells have been discussed previously (1).

\section{SUMMARY}

Twenty-one isolated normal kidneys were perfused with oxygenated, "biochemically supported" blood at pressures ranging between 167 and 192 $\mathrm{mm} . \mathrm{Hg}$. The degree of granulation of the renal juxtaglomerular cells (the juxtaglomerular index) dropped on the average from 44 to 26 during the one to four hour perfusion at these high pressures. Sixteen similar isolated kidneys were perfused at pressures ranging between 82 and $85 \mathrm{~mm}$. $\mathrm{Hg}$. In these kidneys, the average JG index was 43 at the start of the perfusion and still remained 43 at the end of the perfusion. The difference between the two groups was highly significant $\left(p<10^{-12}\right)$. Thus, high perfusion pressures produce marked degranulation of the juxtaglomerular cells in a short period of time, while perfusion at fairly normal pressures produces no change in juxtaglomerular granulation.

Supplementary experiments indicate that the degranulation of juxtaglomerular cells at high perfusion pressures is not caused by an augmented secretion of the adrenal, is not caused by 
the release of humoral substances into the renal vein, and is not related to the degree of hemolysis in the experiment.

These observations are compatible with the theory that the juxtaglomerular cells can act as baro-receptors, changing their rate of secretion as the level of arterial pressure changes.

\section{REFERENCES}

1. Tobian, L., Thompson, J., Twedt, R., and Janecek, J. The granulation of juxtaglomerular cells in renal hypertension, desoxycorticosterone and postdesoxycorticosterone hypertension, adrenal regeneration hypertension, and adrenal insufficiency. J. clin. Invest. $1958,37,660$.
2. Haddy, F., Scott, J., Fleishman, M., and Emanuel, D. Effect of change in blood flow rate upon renal vascular resistance. J. Lab. clin. Med. 1957, 50, 822.

3. Hartroft, P. M., and Hartroft, W. S. Studies on renal juxtaglomerular cells. I. Variations produced by sodium chloride and desoxycorticosterone acetate. J. exp. Med. 1953, 97, 415.

4. Bard, P. Medical Physiology, 10th ed. St. Louis, C. V. Mosby, 1956, pp. 110-111.

5. Dunihue, F. W., and Robertson, W. Van B. The effect of desoxycorticosterone acetate and of sodium on the juxtaglomerular apparatus. Endocrinology 1957, 61, 293.

6. Sarnoff, S. J., and Yamada, S. I. Evidence for abdominal pressoreceptors with special reference to the pancreas. Fed. Proc. 1958, 17, 141.

\section{ANNOUNCEMENTS OF MEETINGS}

The Fifty-First Annual Meeting of THE AMERICAN SOCIETY FOR CLINICAL INVESTIGATION will be held in Atlantic City, N. J., on Monday, May 4, 1959, at 9:00 A.M. at the Casino Theater on the Steel Pier.

The Sixteenth Annual Meeting of THE AMERICAN FEDERATION FOR CLINICAL RESEARCH will be held in Atlantic City, N. J., at the Casino Theater on the Steel Pier on Sunday, May 3, 1959, at 9:00 A.M.

THE ASSOCIATION OF AMERICAN PHYSICIANS will hold its Seventy-Second Annual Meeting in Altantic City, N. J., at the Casino Theater on the Steel Pier on Tuesday, May 5, 1959, at 9:30 A.M. and in the Vernon Room, Chalfonte-Haddon Hall, on Wednesday, May 6, 1959, at 9:30 A.M. 